\title{
Esse e outros campos: a construção do arquivo visual dos campos de concentração nazistas
}

Carolina Fernandes ${ }^{1}$

Résumé: Cet article vise à comprendre le travail de la lecture de l'archive dans son rapport à la mémoire, à la matérialité visuelle et à son mode de circulation. Comme l'objet de l'analyse, on a été sélectionné l'archive visuelle des camps de concentration nazis, en particulier le camp d'Auschwitz. Autour de celui entrent en conflit les effets de sens camp d'extermination et de scénario de moments de détente des officiers allemands. Ce conflit des interprétations est géré par la formation discursive qui organise le travail de la lecture de cet archive, en déterminant ce qui peut et ne peut pas appartenir à cet archive. Le contrôle sur les gestes de la lecture de l'archive est ce qui détermine le maintien de certains fil narratif dans la mémoire collective des camps de concentration, en effaçant d'autres sens qui sont oubliés dans l'interdiscours. Ces sens exclus, même si récupéré par le travail de mémoire discursive, sont affectés par les mécanismes idéologiques qui contrôlent la lecture de l'archive.

Mots-clés: archive; image; mémoire; camp de concentration.

Resumo: Este artigo objetiva compreender o trabalho da leitura de arquivo em sua relação com a memória, com a materialidade visual e com seu modo de circulação. Como objeto de análise foi selecionado o arquivo visual dos campos de concentração nazistas, em especial, o campo de Auschwitz. Em torno deste, entram em conflito os efeitos de sentido de campo de extermínio e cenário de momentos de descontração dos oficiais alemães. Essa disputa de interpretações é gerenciada pela formação discursiva que organiza o trabalho de leitura desse arquivo, determinado o que pode e o que não pode pertencer a esse arquivo. $\mathrm{O}$ controle sobre os gestos de leitura do arquivo é o que determina a manutenção de certo fio narrativo na memória coletiva dos campos de concentração, apagando outros sentidos que ficam esquecidos no interdiscurso. Esses sentidos excluídos, mesmo quando recuperados pelo trabalho da memória discursiva, são afetados pelos mecanismos ideológicos que controlam a leitura do arquivo.

Palavras-chave: arquivo; imagem; memória; campos de concentração.

Um início de reticências...

A noção de arquivo em AD já é operacional na teoria desde sua fundação, visto que remete a um conjunto de textos os quais são a base de toda análise. Acessamos os discursos por meio de sua materialidade, ou seja, pelos textos de natureza diversa que carregam as marcas do processo discursivo. Esses textos circulam de modo disperso e são reunidos por nós, analistas, numa espécie de arquivo de pesquisa, que usamos, conforme Guilhaumou e Maldidier (2010), para construir o corpus de análise. Mas há também o arquivo que

1 Professora da Universidade Federal do Pampa (UNIPAMPA); Doutora em Letras pela Universidade Federal do Rio Grande do Sul (UFRGS). 


\section{Conexão Letras}

circula nas redes virtuais, na mídia, nas ruas, nos livros escolares, há conjuntos de textos que são significados e agrupados em certas tramas de sentido para significar e nos fazer rememorar fatos históricos, memórias familiares ou ainda histórias pessoais.

Este artigo se pauta no trabalho de leitura do arquivo visual dos campos de concentração nazistas para a construção da memória coletiva sobre esses campos que serviram de palco aos maus-tratos, torturas e assassinatos provocados pelos oficiais do exército de Adolf Hitler. O cenário desses eventos mais conhecido foi o campo de concentração de Auschwitz, considerado o maior campo de extermínio da Europa, localizado ao sul da Polônia. A fama de Auschwitz veio por meio das imagens captadas do local logo após a chegada do exército dos aliados que fizeram questão de retratar em vídeos e em fotografias as atrocidades cometidas pelos nazistas marcadas nos corpos dos mortos e dos sobreviventes.

Neste texto, pretende-se refletir sobre a noção de arquivo relacionada à memória discursiva e à memória coletiva ou histórica que se construiu para esses campos, fazendo circular sentidos sedimentados ao passo que se apagam outros sentidos também possíveis, mas negados pelos mecanismos ideológicos que regulam esse arquivo. A fim de desenvolver as análises, foi preciso recortar sequências discursivas (SDs) ${ }^{2}$ do arquivo visual que pudessem representar o processo discursivo da leitura e construção desse arquivo. Para isso, optou-se por recortar SDs do documentário Memória dos campos, do arquivo virtual de imagens gerado pelo site de buscas Google.com, de uma reportagem do Jornal $O$ Globo e do acervo do Museu do Holocausto em Washington. Operou-se o recorte tendo por base a instauração de gestos de leitura antagônicos no interior mesmo do arquivo visual dos campos de concentração nazistas.

\section{Revisitando o conceito de arquivo}

Estamos a todo tempo lendo arquivos, arquivos de textos da própria $\mathrm{AD}$, arquivos de textos sobre determinado assunto, arquivos produzidos pela mídia, pelo aparato escolar, jurídico ou mesmo nosso arquivo pessoal que construímos reunindo textos diversos em torno de um tema comum. Dessa forma, a noção de arquivo é entendida, como propõe Pêcheux (2010, p. 51) "no sentido amplo de "campo de documentos pertinentes e disponíveis sobre uma mesma questão". O campo de documentos que forma um arquivo é regulado por um trabalho de leitura de arquivos, que gerencia as possibilidades de interpretação para esses textos. Segundo Pêcheux:

Por tradição, os profissionais da leitura de arquivos são 'literatos' (historiadores, filósofos, pessoas de letras) que têm o hábito de contornar a própria questão da leitura regulando-a num ímpeto, porque praticam cada um deles sua própria leitura (singular e solitária) construindo o seu mundo de arquivos. (Pêcheux, 2010, p. 50).

E esse mundo de arquivos é compartilhado com outros leitores que se colocam na posição de intérpretes da leitura do outro, ou seja, Pêcheux propõe que há uma divisão social do trabalho de leitura que separa os autorizados a ler e a interpretar de um lado, e os autorizados a reproduzir e a copiar essa leitura de outro. Essa restrição da atividade de interpretação gera o efeito de leitura literal, o efeito de que há apenas um único sentido para tal texto, posto como "documento". Para Pêcheux (idem, p. 51), é papel do analista de discurso questionar essas leituras impostas (as ditas literais), reconstruindo "a história dos gestos de leitura subjacente à construção do arquivo, de sua apreensão e acesso". Para a análise

2 Orlandi (1984, p.121) define sequência discursiva como sendo "uma unidade discursiva que se constitui de fragmentos correlacionados de linguagem-e-situação". E observa ainda que esta é construída pela ação e recorte que varia conforme "os diferentes tipos de discurso, segundo a configuração das condições de produção e se faz de acordo com o objetivo da análise" (ibdem). 
do discurso, então, é fundamental investigar o percurso dos sentidos que tornam evidentes determinado gesto de leitura, tendo em vista a promoção de uma leitura interpretativa considerada por Pêcheux (ibidem) como um "espaço polêmico das maneiras de ler". O trabalho de construção de um arquivo não é, portanto, espaço neutro, mas marcado pelo processo ideológico de direcionamento dos sentidos e de construção da memória social gerida pelos aparelhos de poder de nossa sociedade, como as instituições escolares, os museus, as bibliotecas. O termo memória social é usado conforme a definição de Mariani (1998):

\begin{abstract}
Entendemos por memória social um processo histórico resultante de uma disputa de interpretações para os acontecimentos presentes ou já ocorridos, sendo que, como resultado do processo, ocorre a predominância de uma de tais interpretações e um (às vezes aparente) esquecimento das demais. Naturaliza-se, assim, um sentido 'comum' à sociedade, ou, em outras palavras, mantém-se imaginariamente o fio de uma lógica narrativa. (Mariani, 1998, p. 34)
\end{abstract}

A manutenção de sentidos comuns e o apagamento de outros sentidos da esfera social imobilizam o fluxo de significados para certas narrativas que passam a criar o efeito de memória oficial, ou ainda da memória histórica oficial. São esses sentidos controlados que tornam evidentes certos fatos históricos, abafando outras vozes que poderiam contar outras histórias, outras versões para o mesmo fato, como a morte do presidente João Goulart que agora começa a ser alvo de questionamento da sociedade brasileira em virtude das investigações feitas pela da Comissão Nacional da Verdade ${ }^{3}$ que, através dos restos mortais do ex-presidente, busca apurar a real causa de sua morte tendo em vista a possibilidade de ele ter sido assassinado. Neste caso, foi preciso um aparato institucional para mover os sentidos historicizados e provocar, pelo menos, a desconfiança sobre o absolutismo da história oficial. Desse modo, conclui Mariani (idem, p. 35) que a memória histórica oficial está "sempre efetuando gestos de exclusão a tudo que possa escapar ao exercício do poder", o que produz um efeito de realidade, uma normalidade semântica para o logicamente estável do discurso imobilizado.

Ao percorrer o arquivo visual dos campos de concentração nazistas que estão disponíveis na internet, pode-se notar como a organização do trabalho da leitura trata em massa as imagens desse evento, gerenciando os sentidos e conduzindo-os a uma mesma interpretação. Para "livrar o discurso de suas ambiguidades" (Pêcheux, 2010, p. 55), é preciso fazer exclusões, mas esses sentidos podem ressurgir pelo trabalho da memória discursiva que recupera do interdiscurso os enunciados já ditos ou vistos que estavam lá esquecidos. Esse retorno é igualmente gerenciado pelas formações discursivas que regulam os gestos de leitura. As formações discursivas (FDs) são as matrizes de sentido que determinam o que pode e deve ser dito em certa conjuntura social (Pêcheux e Fuchs, 1993), isto é, são redes significantes determinadas pela ideologia de certa formação social que regula para si própria sua manutenção e deslocamento.

Desse modo, a memória discursiva não se confunde com a memória social ou a memória psicológica, pois está em relação com o interdiscurso, com a repetição e circulação dos enunciados. Para Orlandi (2002, p. 31), a memória do discurso é "o saber discursivo que torna possível todo dizer e que retorna sob a forma do preconstruído, o já-dito que está na base do dizível, sustentando cada tomada da palavra". Nessa perspectiva, veremos os efeitos do trabalho da memória discursiva na leitura do arquivo visual dos campos de concentração nazistas.

3 A Comissão Nacional da Verdade foi criada pela Lei 12528/2011 e instituída em 16 de maio de 2012 com o propósito de apurar violações dos Direitos Humanos ocorridas no Brasil entre 18 de setembro de 1946 e 5 de outubro de 1988. Informações retiradas de:<http://www.cnv.gov.br/index.php>. Acessado em 09/02/2014. 


\section{$2 \mathrm{O}$ arquivo visual dos campos de concentração e suas leituras}

A imagem é a linguagem dileta das mídias. Tudo se ilustra para ficar mais atrativo ao olhar do leitor, assim divulgam-se fotos, vídeos, montagens, desenhos. E com as redes sociais, esse modo de circulação dos discursos é ainda mais usual. Além dos livros, filmes, seriados de TV, sempre há quem lembre da Segunda Guerra e divulgue uma imagem chocante na internet para alimentar os arquivos visuais e reforçar a memória coletiva construída para esse evento histórico. No dia 27 de janeiro, houve a circulação em série desse arquivo visual pela web. E-mails e páginas nas redes sociais foram invadidos por imagens dos campos de concentração nazistas relembrando as vítimas do holocausto juntamente com mensagens de repúdio ao ódio e à intolerância. Essa circulação datada se refere ao fato de que, neste dia, no ano de 1945, começaram a ser libertados pelas tropas aliadas os prisioneiros dos campos de concentração nazista onde eram torturados e mortos através de ferramentas de assassinato em massa como as câmaras de gás. Na ocasião da libertação das vítimas, várias imagens foram captadas para mostrar ao mundo o tratamento desumano que lhes davam os nazistas. Os maus-tratos causados a seres-humanos marcaram os corpos empilhados nas covas coletivas ou mesmo aqueles corpos debilitados dos sobreviventes que tentavam se sustentar sobre as próprias pernas, às vezes sem sucesso.

Nesta mesma data, está previsto para 2015 o lançamento oficial do documentário censurado de Alfred Hitchcock ${ }^{4}$. Conhecido por Memória dos campos, o documentário mostra o flagelo dos prisioneiros, exibe os cadáveres das vítimas sendo carregados pelos soldados ingleses e soviéticos e até por civis alemães. As imagens são chocantes, grande parte do vídeo é dedicada à exibição de corpos esqueléticos e nus que eram carregados nos ombros ou mesmo arrastados e jogados sobre pilhas de outros corpos em osso e pele, como se fosse um aterro sanitário de lixo humano (ver sequência discursiva SD $01^{5}$ ).

SD 01

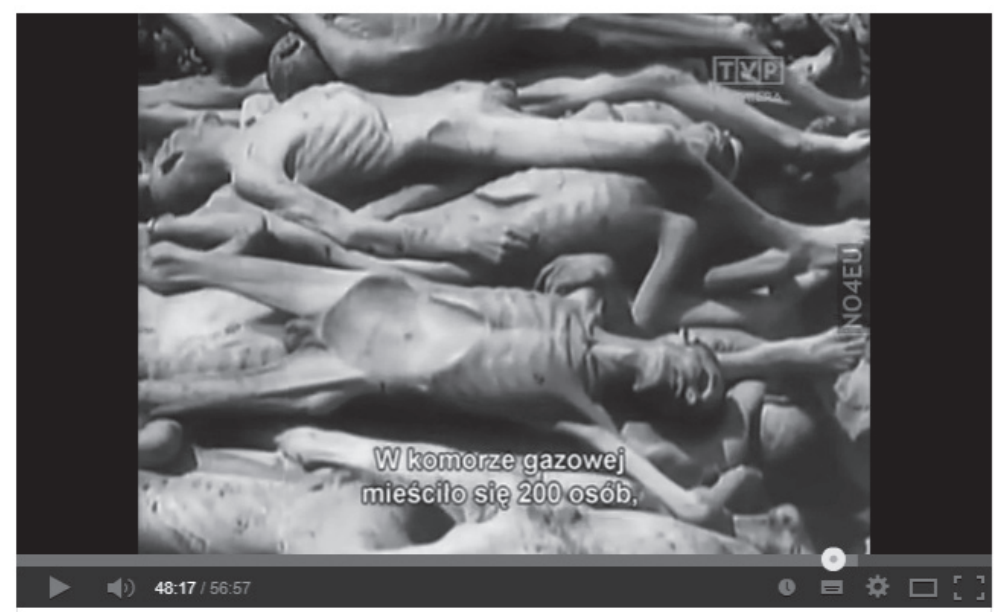

4 Memory of the Camps. Disponível em: <http://www.youtube.com/watch?v=3vYJ2rh53BQ\#t=1014>. Acessado em 28/01/2014.

5 United States Holocaust Memorial Museum. Collections highligth: Auschwitz through the lens of the SS. Exposições on line. Disponível em <http://www.ushmm.org/wlc/en/media_ph.php?MediaId=6412>. Acessado em 09/02/2014. 

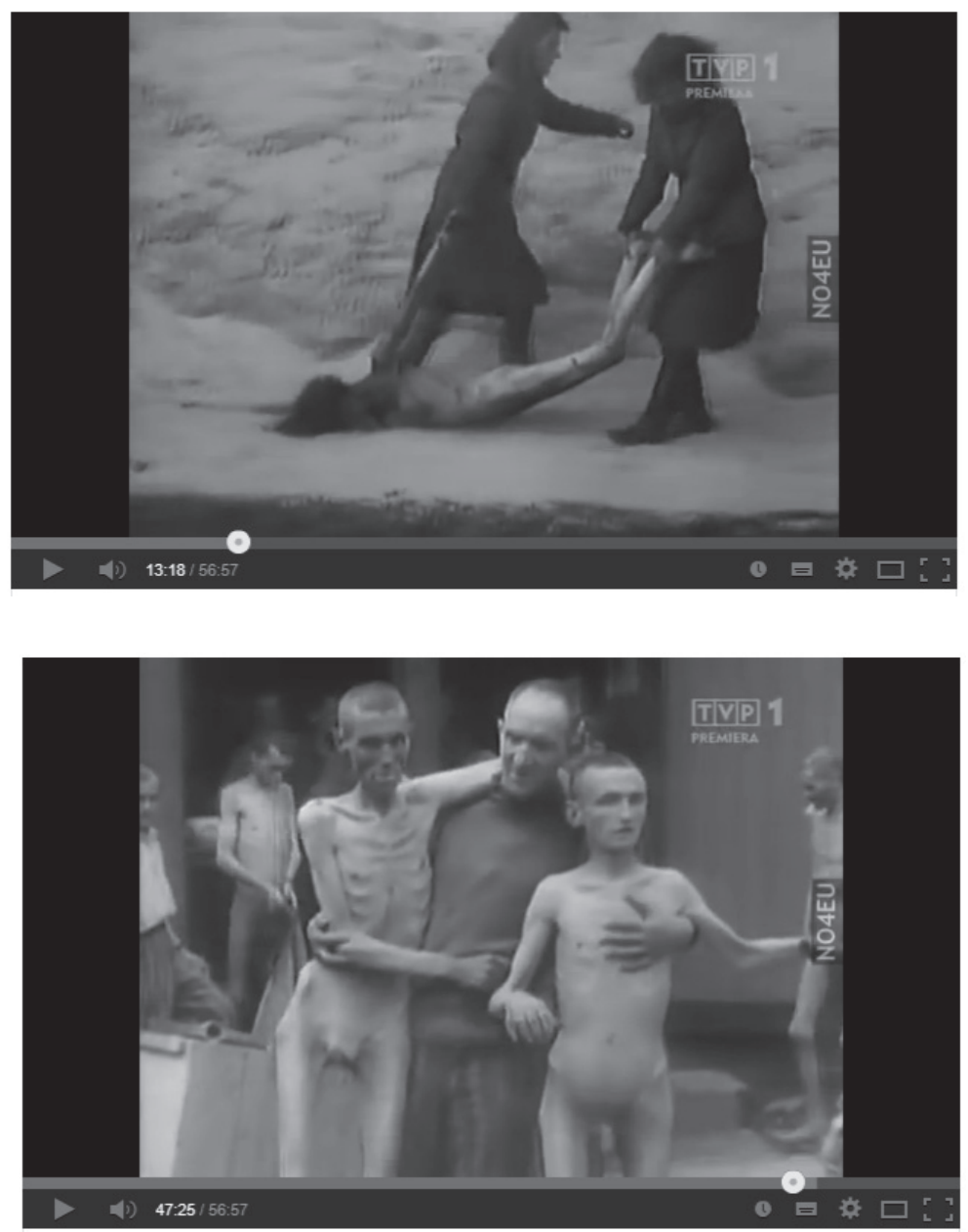

Rodada em preto e branco, a película produz o efeito do horror e comoção pela morte e tortura de tantas pessoas. As vítimas mostram os rostos entre os arames de cerca farpada, revelam os olhos sem brilho, esmorecidos. A nudez do corpo humano é repetidamente exibida sem censura, são como animais expostos em pele. Devido à brutalidade das imagens captadas, o documentário foi censurado na época e teve em 70 anos uma única exibição, em versão incompleta, no festival de cinema de Berlim de $1984^{6}$, mas agora está disponível na web junto a outros tantos vídeos e fotografias sobre as atrocidades do exército de Hitler.

$\mathrm{O}$ arquivo visual dos campos de concentração armazena infinidades de imagens, mas todas elas exibem a debilidade dos corpos das vítimas e a brutalidade com que agiram sobre os esses corpos as doenças, a desnutrição e mesmo a morte. A pesquisa de imagens gerada pelo site de buscas Google.com (SD 02) torna evidente o gesto de leitura sobre o arquivo visual dos campos de concentração: eram campos de extermínio.

6 Informações consultadas em: http://www.folhasocial.com/2014/01/o-filme-com-imagens-chocantes-sobre-o.html. 


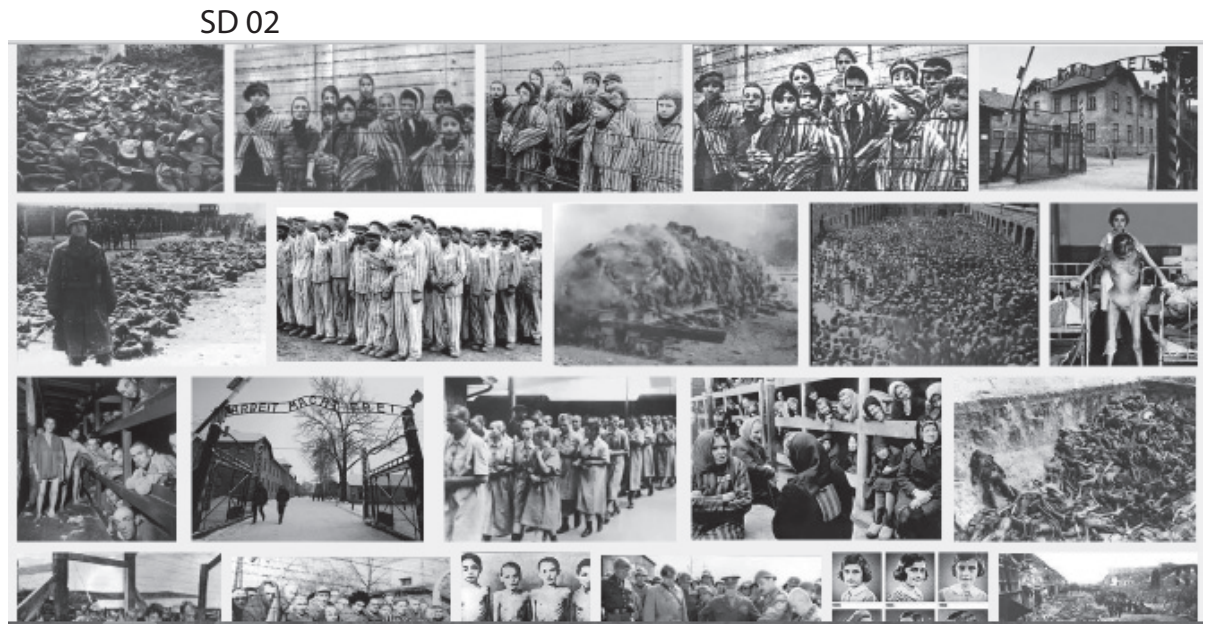

Sobre o tratamento em massa do arquivo textual, Pêcheux (2010, p. 52) ponderou que o desenvolvimento de métodos de reprodução massiva, seja com fins estatais ou comerciais, tornam os arquivos "facilmente comunicáveis, transmissíveis e reproduzíveis", produzindo com maior amplitude o efeito de evidência. Dessa forma, como analisado em trabalho anterior (Fernandes, 2009), por mais que haja dispersão de discursos no ciberespaço, este não é um lugar isento da regulação dos aparelhos ideológicos que atuam para gerenciar os gestos interpretativos e instaurar a leitura literal. Cada hipertexto "funciona como um espaço virtual regulado onde a leitura de arquivo se encontra limitada e direcionada de modo a compreender uma ordem parafrástica de repetição" (idem, p. 120).

Por outro lado, como o interdiscurso, o ciberespaço abriga todos os dizeres, inclusive os que estão excluídos de um hipertexto a outro por meio de FD antagônicas. É o caso do discurso que nega a ocorrência do Holocausto judaico. Blogs e páginas em redes sociais sob títulos como: A mentira do Holocausto; Holocausto judeu, a mentira do século XXI; A grande farsa do holocausto judaico ${ }^{7}$, divulgam um discurso de oposição ao genocídio do povo judeu, argumentando que o número maior de vítimas foi de não-judeus e que fotos e estatísticas foram adulteradas para agravar o efeito da guerra. Isso significaria que as imagens chocantes dos mortos e dos sobreviventes não seriam apenas de judeus. No entanto, a leitura literal produz um efeito de referencialidade que reúne todas essas imagens significando cada corpo maltratado como sendo de um corpo judeu, isto é, todos representando uma única posição-sujeito. $\mathrm{O}$ discurso das organizações judaicas acusa essa interpretação de ser uma "conspiração antissemita", e, na Europa, o sujeito pode responder criminalmente por esse gesto de interpretação. Essas contradições instauram o conflito ideológico no próprio trabalho de leitura do arquivo. Nesse contexto, segundo Nunes (2007 p. 375), o arquivo "é tido como um espaço de polêmica, em que se confrontam as posições interpretativas".

Discursos como os das sequências discursivas a seguir tentam desfazer a polêmica, combatendo essa FD que nega o holocausto por meio da repetição das imagens dos corpos maltratados.

7 Exemplo de um blog consultado: http://verdade1945.blogspot.com.br/2007/10/grande-farsa-do-holocausto-judeu.html 
SD 03

"Todos os anos, no aniversário da libertação do campo de concentração de Auschwitz, relembramos as vítimas do Holocausto. Recordamos o sofrimento de milhões de pessoas inocentes, e realçamos os perigos do antissemitismo e ódio de qualquer espécie" - Ban Ki-moon, secretário-geral da ONU (27/01/2014).

SD 04

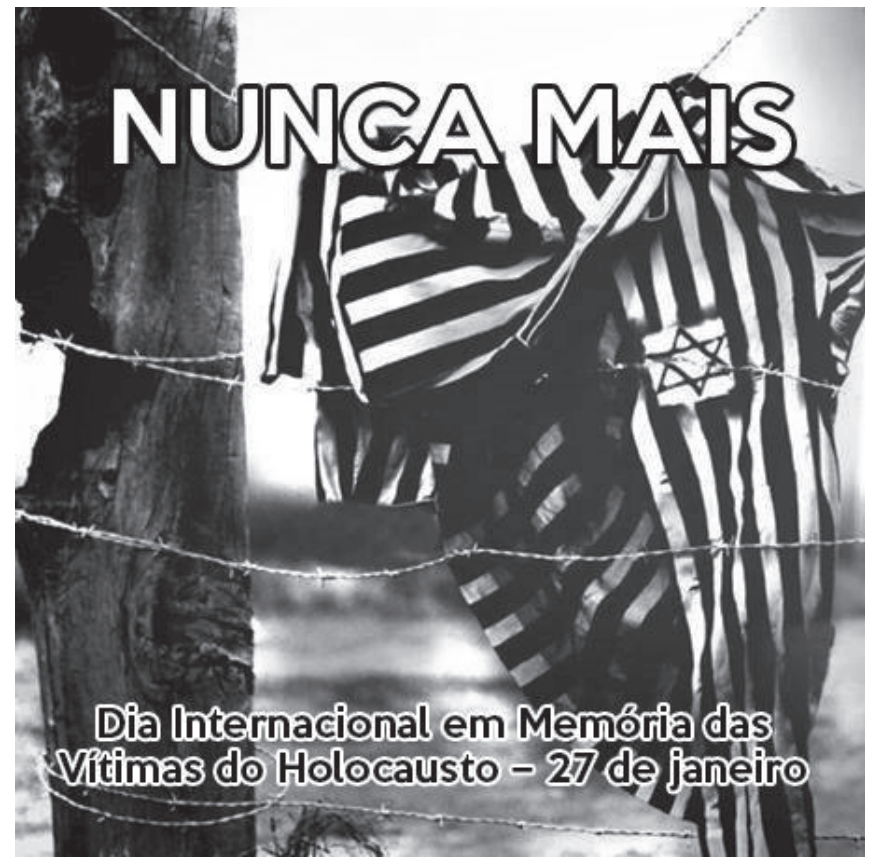

Banner comemorativo ${ }^{8}$

\section{SD 05}

É uma questão de História lembrar que, quando o Supremo Comandante das Forças aliadas, General Dwight D. Eisenhower encontrou as vítimas dos campos de concentração, ordenou que fosse feito o maior número possível de fotos, e fez com que os alemães das cidades vizinhas fossem guiados até aqueles campos e até mesmo enterrassem os mortos. Este email está a ser enviado como um alerta, em memória dos 6 milhões de judeus, 20 milhões de russos, 10 milhões de cristãos, 1900 padres católicos e muitas Testemunhas de Jeová, resumindo SERES HUMANOS, que foram assassinados, massacrados, violentados, queimados, mortos à fome e humilhados, enquanto Alemanha e Rússia olhavam em outras direcções. Agora, mais do que nunca, com o Irã, entre outros, sustentando que "o holocausto foi um mito", torna-se imperativo fazer com que o mundo jamais esqueça. A intenção de enviar este e-mail é de que ele seja lido por, pelo menos, 40 milhões de pessoas em todo mundo. Se você também está ciente, então ajude a enviar o email para todos que forem possíveis. Traduza-o para outras línguas se for o caso! Não o apague!

8 Retirado de: <https://fbcdn-sphotos-d-a.akamaihd.net/hphotos-ak-prn2/1505170_719554114729079_2126 168492 n.jpg $>$. 


\section{Conexão Letras}

As SDs acima tomam o "Dia Internacional em Memória das Vítimas do Holocausto" como justificativa para fazer circular tantas imagens dos prisioneiros, com o propósito anunciado de combater o antissemitismo e evitar novas práticas de extermínio. Além disso, a sequência de imagens aliada ao discurso verbal inflamado contra os maus-tratos aos detidos nos campos de concentração sustentam e saturam o efeito de sentido de que os campos de concentração eram campos de extermínio do povo judeu. Na fala do secretário da ONU, o enunciado "Recordamos o sofrimento de milhões de pessoas inocentes, e realçamos os perigos do antissemitismo e ódio de qualquer espécie" (SD 03) e no banner em letras garrafais: "Nunca mais" (SD 04), ressoam na mesma matriz de sentidos daqueles enunciados trazidos na SD 05. Essa última sequência foi recortada de um e-mail enviado junto a várias imagens recuperadas do arquivo virtual de imagens gerado por sites de busca como o Google.com. A autoria da mensagem do e-mail é anônima e percebe-se que foi traduzida para o português de Portugal, conforme a própria orientação de fazer a tradução para outras línguas, de modo a atingir mais pessoas e de diferentes nacionalidades. A massificação da circulação desse discurso objetiva fazer abafar e apagar o discurso de negação do Holocausto que ameaça a sustentação da memória histórica oficial. O próprio texto traz a contradição entre os números de mortos e a teoria do genocídio, mas a produção do efeito de horror é que prevalece devido à especificidade da materialidade visual ser mais impactante. As imagens "pesam" mais que as palavras por que capturar o olhar do leitor como já observou Rolan Barthes (1984).

O gerenciamento dos modos de ler o arquivo visual dos campos de concentração, devido a sua ampla e repetida circulação nos meios de comunicação e internet, assegura o sentido do holocausto, distinguindo duas posições-sujeito: as vítimas do holocausto de um lado e seus carrascos atrozes de outro.

Entretanto, vídeos como Memória dos campos ou arquivos visuais gerados por sites de busca não são a única forma de retratar e narrar a história dos campos de concentração, há arquivos pessoais de oficiais do exército nazista que contam outras histórias, paralelas às mortes e aos maus-tratos, que estão apagadas desse arquivo oficial.

Ao lado de artefatos e documentos recolhidos dos próprios campos de concentração instalados na Europa, o Museu do Holocausto em Washington, EUA, exibe fotografias de oficiais das tropas da SS (Schutzstaffel, em português "tropas de proteção pessoal" de Hitler) em momentos de descontração na casa de repouso junto ao campo de concentração em Auschwitz, considerado o maior campo de extermínio da Europa, e de onde se capturaram várias das imagens impactantes do arquivo visual sobre a Segunda Guerra. As fotografias pertenciam a um oficial da SS, chamado Karl-Friedrich Höcker, e, apesar de exibir a imagem de pessoas alegres e sorridentes, produz o efeito de horror pela obstinação ao extermínio como sugere a reportagem do jornal $O$ Globo do dia 27 de setembro de 2007 (SD 07), também foi exibida no Jornal Nacional da rede Globo de televisão no mesmo dia.

\section{SD 06}

\section{Descontração em Auschwitz ${ }^{9}$}

por Luís Fernando Silva Pinto, de Washington (27/09/2007)

A crueldade do regime nazista em imagens inéditas: fotografias do cotidiano dos militares no campo de concentração revelam a indiferença dos oficiais alemães à matança de judeus em Auschwitz.

Fotos de militares em clima de descontração poderiam ser apenas lembranças do

9 Disponível em: <http://g1.globo.com/jornalhoje/0,,MUL1157146-16022,00-

DESCONTRACAO+EM+AUSCHWITZ.html>. Acessado em 30/09/2007. 
passado, mas são imagens revoltantes. Os homens são oficiais nazistas; as mulheres, empregadas do serviço de informação de Hitler. Eles se divertiam na casa de repouso dos militares no campo de concentração de Auschwitz, na Polônia, no fim de 1944.

Nos dias em que a maioria das fotos foi tirada, milhares de judeus da Hungria eram executados; quem sobrevivia bebia água suja e disputava pedaços de pão... Já entre os oficiais nazistas, não faltavam bons charutos, vinhos e música.

As fotos, inéditas, acabam de ser doadas ao Museu do Holocausto, em Washington. Elas foram encontradas 60 anos atrás por um oficial americano num apartamento em Frankfurt. Meses atrás, ele ligou para o museu, conversou com a pesquisadora Rebecca Erbelding e enviou para ela todo o material.

Rebecca diz que as fotos mostram mais do que oficiais em momentos de lazer: elas documentam a obstinação do regime nazista em assassinar seres humanos.

O álbum pertencia a Karl Hocker, que era o ajudante de ordens de Richard Baer, o comandante do campo.

O homem mais famoso a aparecer nas fotos é Joseph Mengele, que depois da guerra se refugiou no Brasil e morreu em 1979. Quando a foto foi tirada, ele era conhecido como o "anjo da morte", por causa das monstruosas experiências médicas que fazia com os prisioneiros do campo; Mengele torturava, mutilava e enlouquecia prisioneiros para saber os limites da resistência humana. Nas fotos, ele aparece sempre tranquilo, sorridente.

Joseph Robert White, historiador dos campos de concentração do regime nazista, diz que as fotos mostram como é fácil cometer genocídio e, ao mesmo tempo, "manter uma atitude absolutamente normal".

As 119 fotos dos oficiais alemães estão sendo comparadas com fotos tiradas nos mesmos dias, só que no lado dos prisioneiros. Quase 200 dessas fotos de vítimas sobreviveram à guerra; elas nem mostram todos os horrores de Auschwitz, mas revelam como o extermínio dos judeus continuou sem trégua, mesmo nos últimos meses da Segunda Guerra Mundial, quando o regime nazista estava derrotado pelas tropas aliadas e pelos russos.

Na página virtual do jornal $O$ Globo, há um link que remete às fotos exibidas no museu. Eis algumas das fotos comentadas na reportagem na SD 07:

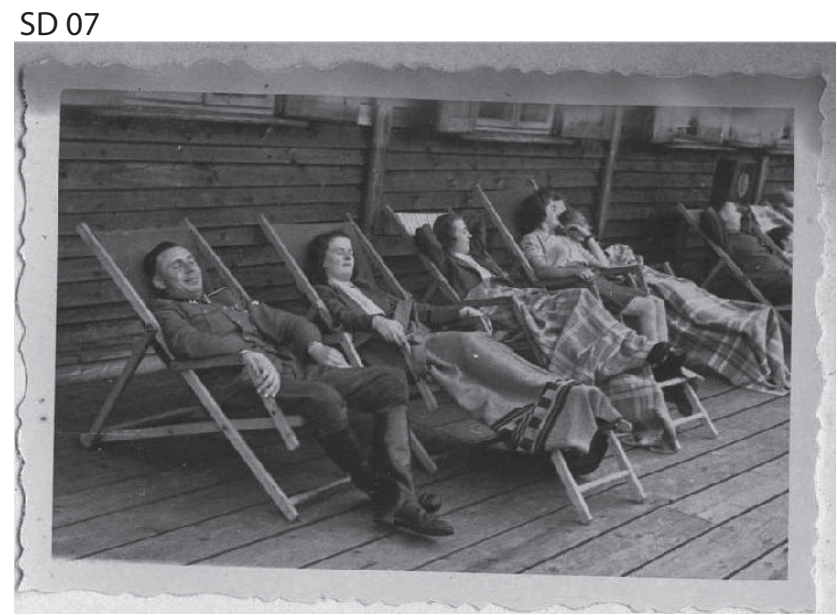

Oficiais relaxados em momento de lazer na casa de repouso dos militares no campo de concentração de Auschwitz, na Polônia, no fim de 1944. 


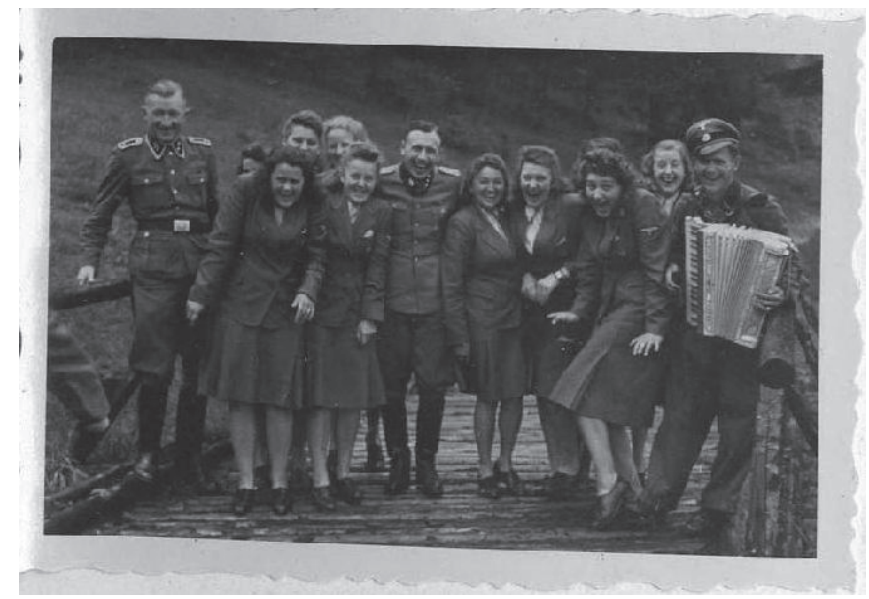

Oficiais se divertindo ao som do acordeom, na chuva.

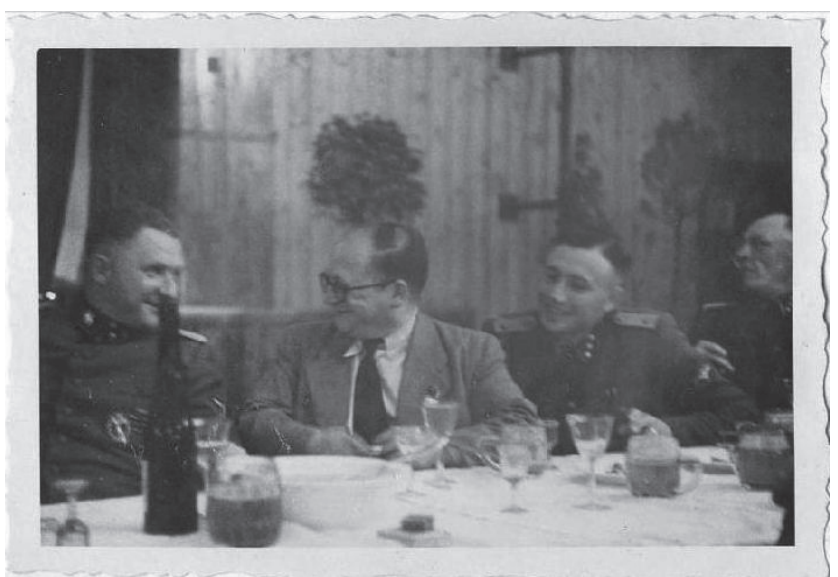

Oficiais em jantar dedicado à inauguração do novo hospital do SS em Auschwitz. Na foto, aparece à direita Richard Baer e o Dr. Carl Clauberg e o oficial Karl Höcker.

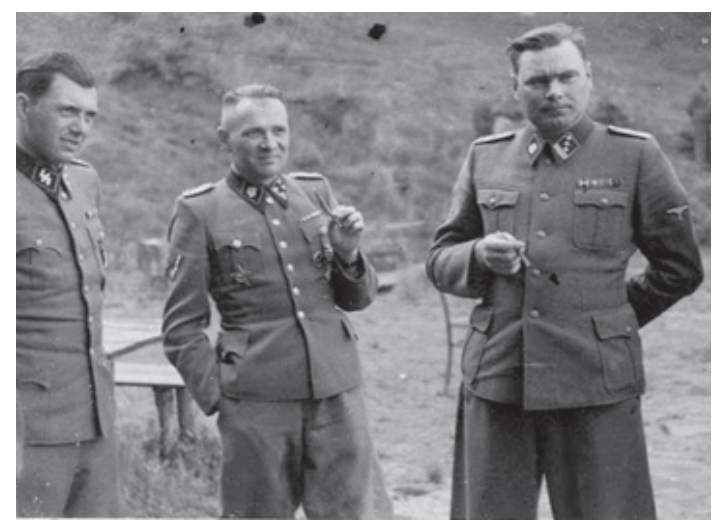

Entre dois SS-oficiais está Joseph Mengele, médico alemão responsável pelas experiências feitas com os prisioneiros. 


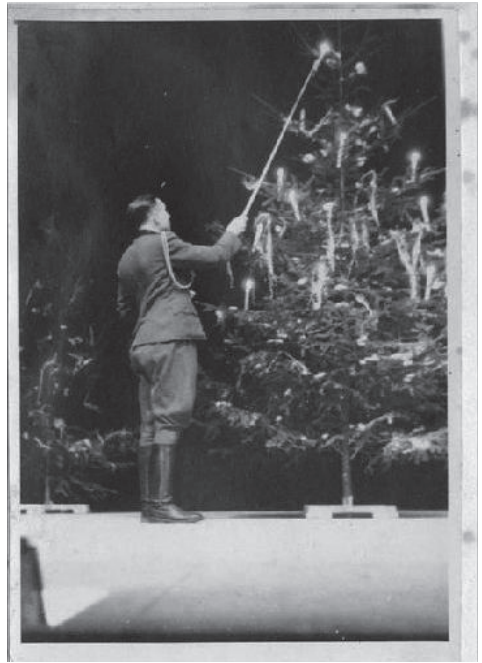

O oficial Karl Höcker acende as velas da árvore de Natal, decoração da casa de repouso para os festejos de final de ano.

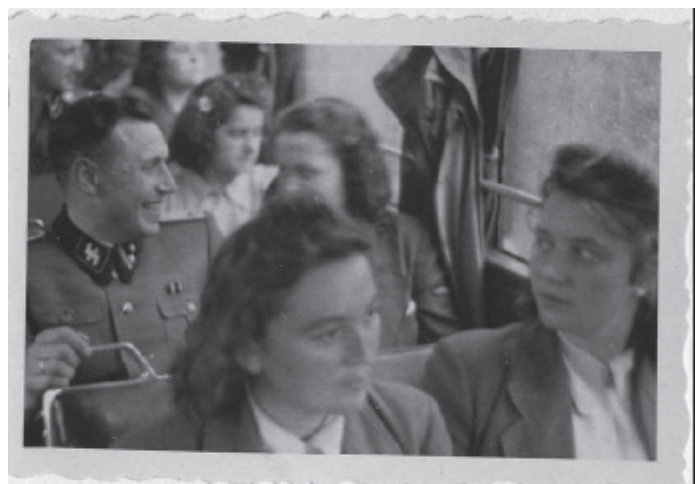

O oficial Karl Höcker e uma oficial da SS Helferinnen (auxiliares femininas) em conversa descontraída.

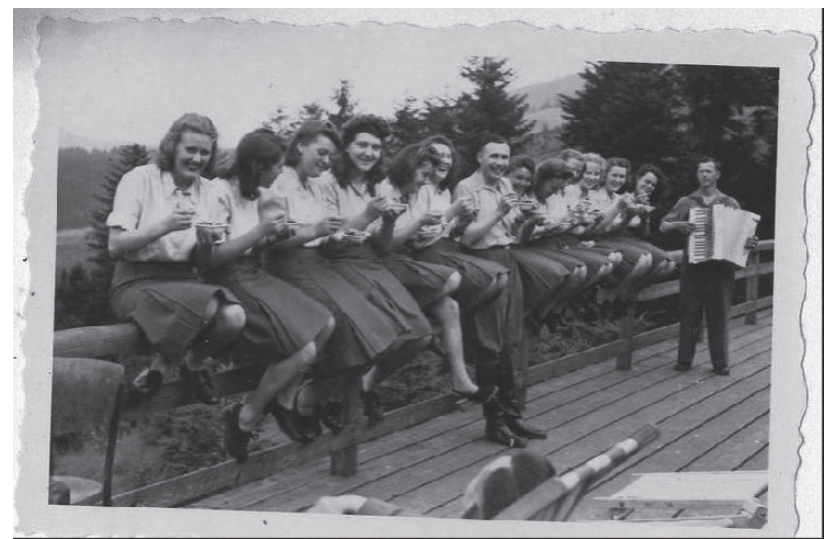

O oficial Karl Höcker e membros do SS Helferinnen (auxiliares femininas) posam saboreando uma sobremesa feita de mirtilo. Ao fundo, um músico toca acordeom. 
As fotografias apresentam os oficiais da SS sempre sorridentes, ora até mesmo rindo em momentos de lazer, repouso ou de diversão. Revelam também o conforto de que dispunham, como cobertores, sobremesas, bebidas e charutos, logo nada lhes faltava, um cenário oposto ao que nossa memória coletiva nos reservou dos campos de concentração. A descontração e alegria evidenciadas nessas fotografias não causaria tanto espanto se não fosse lida na mesma rede de formulações (Courtine, 1981) ${ }^{10}$ que as imagens as quais revelam a forma desumana com que eram tratados seus prisioneiros.

A SD 07, em vários momentos do texto da reportagem, relaciona as duas situações: a dos prisioneiros e a dos militares nazistas, mostrando o abismo entre os lugares ocupados por esses sujeitos. Por essa leitura em contraste, essas fotografias produzem o efeito de horror que as permite ler como sendo revoltantes.

Para reforçar o efeito de "revolta", a função-autor da reportagem integra à discursividade do texto as falas de dois pesquisadores que ocupam a posição dos autorizados a ler e a interpretar o arquivo visual de Auschwitz.

\section{SD 08}

Rebecca diz que as fotos mostram mais do que oficiais em momentos de lazer: elas documentam a obstinação do regime nazista em assassinar seres humanos.

Joseph Robert White, historiador dos campos de concentração do regime nazista, diz que as fotos mostram como é fácil cometer genocídio e, ao mesmo tempo, "manter uma atitude absolutamente normal".

Os enunciados da SD 08 indicam os gestos de leitura para essas imagens: os nazistas obstinavam matar seres humanos e o faziam naturalmente. O sujeito-jornalista ${ }^{11}$ incorpora essas vozes dos estudiosos como o discurso de verdade e encerra, assim, outras possibilidades de leitura.

A desconcentração em jantares, a música ao vivo, os jogos e bebidas, os banhos de sol, a sobremesa compartilhada, o arranjo da árvore de Natal, todas essas imagens contrastam com aquelas dos corpos cadavéricos e empilhados em montanhas de mortos. Há aí a contradição interna no próprio arquivo institucional do Museu do Holocausto em Washington, EUA. No entanto esse conflito é gerenciado na leitura do arquivo virtual do museu, visto que, se formos procurar por "Auschwitz" na ferramenta de busca do site, não são apresentadas as fotografias do álbum de Höcker no resultado da busca, as fotografias aparecem se buscarmos pelo nome do proprietário das fotos ou no domínio exclusivo para essas imagens intitulado: "Coleção destaque: Auschwitz através das lentes da SS".

Observando as fotografias do álbum privado de Höcker, percebemos que ações típicas das emoções humanas como rir poderiam ser vistas apenas como momentos de descontração entre colegas de ofício, de repouso merecido pela árdua tarefa diária. Esse é o sentido que lhe é dado pelas palavras de um descendente do oficial, como consta na SD $09^{12}$.

10 Por rede de formulações, Courtine (1981) entende se tratar de um conjunto de enunciados que ressoam em uma mesma formação discursiva.

11 Vale ressaltar que, em Análise de Discurso, a interpelação ideológica do sujeito, conforme Pêcheux (2009), é inconsciente. Portanto, o sujeito assume uma posição ideológica, mas não toma posicionamento por suas próprias intenções, mas porque assume uma posição-sujeito dada pela ideologia.

12 «Ce sont des photos comme toutes les familles en possèdent. [...] Comme un enfant, je les ai longtemps aimées, comme celles de notre maison de vacance à Solahütte, à trente kilomètres d'Auschwitz, où ma mère, radieuse, admirait mon père en uniforme SS ». Disponível em http://www.lagazettedeberlin.de/4192.html. Acessado em 16/02/2014. 
SD 09

«Estas são fotos como as que qualquer família possui. [...] Quando era criança, eu as olhava por um longo tempo, como as de nossa casa de férias em Solahütte, $30 \mathrm{~km}$ de Auschwitz, onde minha mãe, radiante, admirava meu pai no uniforme da SS".

O arquivo pessoal de Karl Höcker pode ter sido para ele uma agradável recordação dos momentos convividos com os colegas. Pode ter sido para sua família uma boa lembrança do ente querido e lhes inspirar orgulho por sua posição de oficial. Entretanto, essa memória não é coletiva, não se firma entre os sentidos reconhecidos socialmente para esse evento histórico. Não são os risos que a história fará retornar e contará às gerações futuras o que aconteceu naqueles campos ${ }^{13}$.

É desse modo que se distingue a memória histórica oficial da memória discursiva, visto que esta última pode fazer circular todos os sentidos possíveis, mesmo que sejam impossíveis para uma formação discursiva ou outra. A memória discursiva traz do interdiscurso os dizeres já-ditos ou as imagens já vistas, enunciados que podem retornar no eixo intradiscursivo, entretanto o controle desse arquivo se faz por meio de uma memória que se coloca como um consenso, que funciona como um mecanismo ideológico que regula a FD e rejeita os sentidos como a negação do holocausto e a humanidade dos oficiais.

\section{Para concluir...}

O campo de documentos sobre o holocausto que circula na sociedade não abriga as fotografias de Karl Höcker, não torna parte da História as paqueras com jovens oficiais, os jantares, as músicas no fim da tarde ao som do animado acordeom, não mostra a sutileza de uma soneca no alpendre ao lado de moças sorridentes. O campo de documentos do arquivo pessoal de Karl Höcker é outro campo, é um cenário esquecido no interdiscurso e apagado da memória histórica oficial de modo que, para fazer parte do arquivo dos campos de concentração, deve ser lido sob o efeito do horror e da revolta.

A partir das análises, observamos que, pelo trabalho da memória discursiva pode-se recuperar qualquer enunciado ou imagem do interdiscurso, entretanto seus sentidos são regulados por mecanismos ideológicos que controlam o arquivo a fim de construir um efeito de verdade, ou mesmo de realidade, que construirá a memória coletiva. As lembranças de Karl Höcker não são as nossas lembranças, foram apagadas pela formação discursiva (FD) que controla o que pode pertencer ao arquivo dos campos de concentração e o que não pode. Assim, nessa FD, é impossível dar a esses oficiais sentimentos humanos como a alegria e a emoção, eles são vistos como carrascos atrozes obstinados a matar e a torturar pessoas inocentes.

As imagens trazidas à análise neste artigo não esgotam as possibilidades de arquivo sobre o campo de concentração dos nazistas. Esse e outros campos podem surgir, uns mais verdes, mais coloridos, mais amigáveis, outros mais sombrios, mais secos e sem vida. Todos são campos de um mesmo arquivo que revela suas contradições, seus diferentes matizes e matrizes (de sentido). O que a memória oficial nos reservará disso tudo?

13 Essa discussão sobre o trabalho da memória e sua relação com a materialidade visual está mais detalhada no trabalho apresentado no IV Encontro de Estudos da Linguagem e III Encontro Internacional de Estudos da Linguagem (ENELIN), 2011, sob o título: Que horror! Eles se divertiam! Um ensaio sobre os efeitos da imagem como discursivização da história. 
BARTHES, Roland. A câmera clara: nota sobre a fotografia. Rio de Janeiro: Nova Fronteira, 1984. Título original: La chambre Claire, 1980.

COURTINE, Jean-Jaquecs. Analyse du discours politique. Langages, n.61, juin, 1981. FERNANDES, Carolina. O ciberespaço no confronto de sentidos: uma nova leitura de arquivo. In: INDURSKY, Freda et al. (Orgs.). O discurso na contemporaneidade: materialidades e fronteiras. São Carlos: Claraluz, 2009, p. 117-124.

GUILHAUMOU, Jacques; MALDIDIER, Denise. Efeitos do arquivo. A Análise do Discurso no lado da história. In: ORLANDI, Eni et al. (orgs). Gestos de leitura: da história no discurso. 3 ed. Campinas, SP: Editora da UNICAMP, 2010, p. 163-181.

MARIANI, Bethânia. O PCB e a imprensa: os comunistas no imaginário dos jornais (19221989). Rio de Janeiro: Revan, Campinas, SP: UNICAMP, 1998.

NUNES, José Horta. Leitura de arquivo: historicidade e compreensão. In: INDURSKY, Freda et al. (Orgs.). Análise do Discurso no Brasil: mapeando conceitos, confrontando limites. São Carlos: Claraluz, 2007, p.373-380.

ORLANDI, E. P. (1984). Segmentar ou recortar? In: Linguística: questões e controvérsias. Série estudos n.10, Publicação do Curso de Letras do Centro de Ciências Humanas e Letras das Faculdades Integradas de Uberaba, Uberaba, SP, 1984, p. 9-27. . Interpretação: autoria, leitura e efeitos do trabalho simbólico. Petrópolis: Vozes, 1996.

. Análise de Discurso: princípios \& procedimentos. São Paulo: Pontes, 2002.

PÊCHEUX, Michel (1975). Semântica e discurso: uma crítica à afirmação do óbvio. Campinas, São Paulo: Editora da UNICAMP, 2009.

. (1982) Ler o arquivo hoje. In: ORLANDI, Eni et al. (orgs). Gestos de leitura: da história no discurso. Campinas, SP: Editora da UNICAMP, 1994, p. 55-66.

PÊCHEUX, Michel; FUCHS, Cathérinne. (1975). Por uma análise automática do discurso: atualizações e perspectivas. In: GADET, Françoise; HAK, Thomas. (orgs.) Análise do discurso: uma introdução à obra de Michel Pêcheux. Campinas, SP: Editora da UNICAMP, 1993, p.163-187. 